\title{
Risk Analysis of Two Leader Drink Company: PepsiCo and Coca-Cola
}

\author{
Zhuo Zhang ${ }^{1}$ \\ ${ }^{1}$ Monash University, Melbourne, Australia \\ Correspondence: Zhuo Zhang, Monash University, Melbourne, Australia. Tel: 61-45-216-0819.
}

Received: October 22, 2019

Accepted: November 14, 2019

Online Published: December 14, 2019

doi:10.20849/abr.v4i3.686

URL: https://doi.org/10.20849/abr.v4i3.686

\begin{abstract}
The purpose of this report is to introduce and analyze risk factors of PepsiCo and Coca-Cola. By identifying the internal factors involving strategy, information system, contracts and governance and the external factors which include economy, law, customers preference and competitive environment of the two companies, the similarities and differences are given. Then risk taxonomy and analysis are given. In the end, some advice about reducing financial risk are given.
\end{abstract}

Keywords: risk, PepsiCo, Coca-Cola, Bow Tie

\section{Introduction}

\subsection{Overview of the Two Companies and the Industry}

Both PepsiCo, Inc. (PEP) and Coca-Cola Co (KO) belong to the food and beverage industry, and both occupy important positions in this industry. As far as PEP is concerned, PEP is one of the world's leading food and beverage companies serving more than 200 countries and regions worldwide(www.pepsico.com) with a series of complementary portfolio of brands (PEP 10-K Annual Report, 2018). Revenue for the fiscal year ended December 2017 was $\$ 635.25$ billion, according to the company's annual report (MarketLine, 2019). On the other hand, as the main competitor of PEP, $\mathrm{KO}$ also sells beverages and snacks, and its brands and products are also widely distributed in more than 200 countries. The food and beverage industry are an industry with large investment scale, which needs to reduce manufacturing costs with economies of scale to make profits. PEP and KO basically follow a similar business model, known as the " $1+\mathrm{X}$ " model -- one concentrate plant and multiple bottling plants. The bottling plant and the concentrate plant are the lips and teeth of each other, supporting the main production and marketing framework of the two companies.

Founded in 1886 in the United States, KO has over 500 non-alcoholic beverage brands up to now, including sparkling and non-sparkling beverages such as mineral water, fruit juice, instant coffee, and sports drinks. As the world's largest non-alcoholic beverage group, non-alcoholic beverages are its key business. In addition, company sales are distributed worldwide. KO is sold in four major global regions: North America, Asia-pacific, Latin America, Europe, the Middle East and North Africa. And It accounts for $20 \%, 23 \%, 28 \%$ and $29 \%$ of the company's total revenue, respectively. Besides, KO offers different brands of beverages for different countries and regions to meet the needs and preferences of consumers in different regions. For example, KO has introduced Georgia, a coffee brand, for the Japanese market, and Ice Dew, a pure water brand, for the Chinese market. This marketing strategy caters to another's pleasure in all over the world, which helped KO maximize its profitability. PEP is almost the same product type and strategy contract to KO. It distributes its products through retailers to every corner of the world, and through product innovation, acquisitions, and strategic alliances to meet consumers' changing tastes and expectations. The annual reports presented below will confirm how much this strategy has helped PEP improve profitability.

PEP was born in 1898, 12 years after KO.KO has been a market leader in terms of market penetration and brand value, and PEP has been a market challenger. KO has grown rapidly since its founding in the late 19th century. Now, it already has the largest market share of the global soft drink market (44\%) (McKelvey, 2006). Furthermore, according to McKelvey's (2006) view, PEP's purchase of Gatorade from Quaker Oats in December 2000 was further evidence of the company's commitment to expanding its product base, with Gatorade already a major player in the industry. At present, $\mathrm{KO}$ has the upper hand in the overall global $\mathrm{KO}$ market, but sales of 
PEP products are higher in Quebec, Canada, and India, and it is the few places that can surpass KO. As a result, during the ongoing competition between PEP and KO, they already have become the major participant in the industry.

Food engineering released an annual list of the world's top 100 food and beverage companies for 2018 on September 4 (www.foodengineeringmag.com). Judging by the annual turnover of the list, only 28 companies have risen in the rankings since last year. More than half were at least one place behind last year, while 17 were ranked the same. But the above figures do not fully capture what the world's biggest food and beverage company has achieved in the past year. Despite shrinking markets, increasing regulation, rising consumer expectations, and economic uncertainty, the 100 companies on the list still saw total sales increase by $\$ 61$ billion, or $\$ 689$ million per company on average. By revenue, the biggest winner of the year was Anheuser-Busch InBev. In the past year, Anheuser-Busch InBev annual sales grew by more than $\$ 10.92$ billion, placing it in third place. But its revenues are still $\$ 7$ billion less than those of the second-ranked PEP, which earned $\$ 63.53$ billion over the course of the year. KO, by contrast, has struggled. KO fell two places in revenue list, with sales falling to $\$ 35.41$ billion last year from $\$ 41.86$ billion the year before. $\mathrm{KO}$ has faced new pressures over the past few years: sales of fizzy drinks have fallen in America, and countries such as Britain, South Africa, and Ireland have imposed taxes on sugary drinks. Overall, PEP and KO have performed better than most other companies in the industry.

\section{External and Internal Factor Analysis of the Companies}

\subsection{The Strategy and Major Objective of PepsiCo and Coco-cola}

In terms of PepsiCo, it focuses on building powerful brands. PepsiCo connects its brand with world-class partnerships like UEFA Champions League, which attracts more fans and customers (PepsiCo, 2017). In addition, it mainly pays attention to researching activities which include the improvement of new ingredients and innovative products, reforming of the process of manufacturing and enhancement of product quality. The plan can not only increase manufacturing output, but also decrease costs and enhance the efficiency (MarketLine, 2019). Based on marketing strategy, Ventresca, Larsson and Kim (2015) argues that PepsiCo focuses on the interaction with consumers. It holds many marketing campaigns to listen to the demand of customers and think about what products can really help to influence their lifestyle. In addition, PepsiCo also uses predictive and big data to learn about consumers' opinions, which helps the company to produce better products. In terms of Coke-cola, continuing to produce new products is their marketing plan. Coke is committed to make new flavors, all kinds of products are followed by customers. Its strategy focuses on brand awareness. Letting consumers love its brand is the firm's objective. Every day the employees of Coke-cola need to connect with the customers and make them remember the brand. In addition, the corporate also invests a lot of money to advertise and makes great efforts in the digital field, which aims to establish brand awareness and increase brand influence (Gupta, 2011).

\subsection{Modification of Companies' Strategy}

In 2017, the strategy of PepsiCo changed, it aimed to refine food, snack and beverages. PepsiCo decreased saturated fat in snacks and added sugars in beverages. Beverages were made of natural flavors instead of high-fructose corn syrup. The snacks and foods were more healthy and nutrient. The reason why PepsiCo changed the strategy was that it tried to meet the change of demand of consumers. This change would give customers a more healthy lifestyle (MarketLine, 2019). In terms of Coca-Cola, its main strategy is not changed. It also makes new flavor products to attract consumers.

\subsection{The Stakeholders of the Companies and Their Key Objectives}

In terms of Coca-Cola, its stakeholders involve bottling partners, suppliers, consumers, industry, employees, media, investor, the government, NGOs and disclosure organizations (Coca-Cola Co, 2018). Based on PepsiCo, its stakeholder include customers, the government and suppliers.

\subsection{Identification and Analysis of Internal and External Factors in Two Companies}

As a result of the access to the information, the report uses gathering available data to identity internal and external factors of two companies.

In terms of internal factors, policies, objectives and strategy can influence financial results. Form the financial data of Coca-Cola's annual report, new products like coke zero has increased the income of the company. Coca-Cola (2017) notes that the innovation of products is an essential risk factor. Coca-Cola's marketing strategy is to produce new products to attract consumers. If there is no innovation, competition will disappear gradually. But the factor is not adapt to PepsiCo. PepsiCo focuses on the brand which is related to famous partnership instead of reformation. In addition, information system is a considerable risk factor. PepsiCo and 
Coca-Cola all rely on a safe information system. PepsiCo, Inc (2018) notes that if the information system is attacked and the important information is divulged, the losses of the company will be huge. The third risk factor is contractual relationship. If the company is not able to provide satisfactory conditions, employees who have high skills will leave, which gives a negative impact on operations (PepsiCo, Inc, 2018). Based on Coca-Cola, it pays attention to contracts with bottling partners instead of workers. Coca-Cola must offer partners pleasant terms in case labor unrest decreases the firm's business. The final factor is about governance. PepsiCo, Inc (2018) notes that failing to finish acquisitions and joint ventures may results in the reduction of business. It is also adapt to Coca-Cola.

In terms of external factors, change of customer preferences is the first factor. PepsiCo, Inc (2018) illustrates that if consumers alter their preference, the demand of products will have disadvantaged impact, which affects PepsiCo's business. Change of customer preferences is also linked with financial risk which is mentioned in the next part. It relates to market risk. It results in reduction of demand and decrease of market price which increases the risk of losses. Based on PepsiCo, it has the same problem. Coca-Cola Co (2017) argues that the factor also influences its sales. If customers consider health, nutrition and obesity concerns, they will change preferences, which causes that reduction of Coca-Cola's business. The second external factor is legal factor. PepsiCo, Inc (2018) notes that the alternation of the law about processing plastic will enhance the firm's costs, which results in the decrease of demand. Coca Cola has the same risk factor. Not all the products can be recyclable. Changes of laws may have a bad impact in Coca-Cola (Coca-Cola Co, 2017). Moreover, economic factor is not ignored. Terrible economic situation may influence the financial performance of the companies. Coca-Cola $\mathrm{Co}(2017)$ notes that the important part of income is from markets all over the world. The operations outside America occupies 58 percent of total markets. If the economy is not stable and terrible financial situation such as the disadvantaged interest rate appear, the revenue of Coca-Cola will be influence seriously. PEP is also affected by this risk factor. Other low price products may be more popular, which causes that the demand of products reduces (PepsiCo, 2018). Finally, natural and competitive environment are essential risk factors. PepsiCo, Inc (2018) illustrates that the beverage, foods and snacks need to compete with the products of international firms. If there are no competitive advantages, the products will not attract consumers. Coca-Cola Co (2017) also notes that fierce competition will damage its business. As a result of competitors' behaviors, the sales may be limited.

\section{Risk Taxonomy and Risk Analysis}

\subsection{Risk Analysis for PepsiCo and Coca-Cola}

\section{PEPSICO}

\section{Strategic}

In the face of the existence of many similar beverage markets, it is impossible to propose effective means of competition. This has caused Pepsi to be in an advantageous position in the market competition. The company's investment and development in developing countries are particularly important. Neglecting this will lead to limited development of the company. It cannot ignore the company's strategic goals and the culture and traditions of developing countries. Using labels to warn consumers that the firms' products contain certain substances or ingredients will cause that consumers avoid PepsiCo's products because they do not know whether these ingredients or substances are harmful.

\section{Operational}

The political environment in which products are produced, manufactured, distributed, or sold may have unpredictable effects on product sales. In the face of cyber attacking or other network events, if the company's information system cannot be effectively protected, it will cause huge losses to the company's business and reputation.

\section{Financial}

The state may impose or propose a new tax or increase the tax on a product, resulting in increased expenses and increased financial burden. There may be a recession or a slowdown in the economy, for example, business or financial performance may be adversely affected by uncertainties or adverse economic conditions all over the world. PepsiCo's business, financial condition or operational results may be adversely affected by rising costs, supply disruptions or shortages of raw materials, energy, water, and other supplies. Business disruptions can adversely affect PepsiCo's business, financial condition or operational results. PepsiCo, as well as its suppliers and other third parties, including its bots, contract manufacturers, distributors, joint venture partners, and customers, the ability to manufacture, manufacture, transport, distribute and sell products in its portfolio. 


\section{Compliance}

Changes in laws and regulations regarding the use or disposal of plastics or another packaging of PepsiCo's products, for example, restrictions on plastic products have led to a significant drop in sales of the company. Potential liabilities and costs from litigation, claims, legal or regulatory proceedings, inquiries or investigations could have an adverse impact on business, financial condition or results of operations.

\section{COCA-COLA}

\section{Strategic}

The innovation activities were not successful, and no innovation plan was made to attract consumers, resulting in the decline of competitiveness in the market.

Over-reliance on partners and not correctly estimating level of productivity will result in decrease of performance.

Operational

Product safety hidden danger, if the firm or bottling partners do not conform to the applicable product safety and quality standards, or if its products on the market or contaminated or adulterated in any way, Coca-Cola may need to be expensive product recalls and product liability claims and may be limited by negative publicity, which may influence its business. If Coca-Cola fail to protect its information systems from service disruptions, data theft, or security breaches, business may be disrupted. In addition, it may suffer financial losses, and influence Coco-Cola's reputation.

Financial

Sales of sugary drinks have been hit by higher prices as the government raises taxes on them. Increased market competition may limit the ability to gain or maintain market share in global or various local markets due to the actions of competitors. Changes in the retail landscape, or the loss of key retail or catering customers, could negatively impact financial performance. Coca-Cola's industry is being affected by the trend towards consolidation of retail channels, particularly in Europe and America. Exchange rate fluctuations have a huge impact on company's performance. Revenue was affected by deteriorating global credit market conditions and changes in accounting standards.

\section{Compliance}

Changes or non-compliance with laws and regulations applicable to Coca-Cola's products or business operations may increase its costs or reduce net operating income. According to the risk taxonomy, both Pepsi and Coca-Cola's operations are affected by market conditions, especially by the company's position in the market. And due to changes in national regulations and policies, the company's sales will also be affected. In addition, in the face of network information security issues, both companies have certain risks. Comparing the two companies, Coca-Cola seems to rely more on third-party companies, such as packaging, raw materials and transportation. All of which require strong support from third-party companies.

\subsection{Bow Tie Analysis}

Financial risks include liquidity risk, credit risk, market risk and capital risk, which both existed in two companies we analyzed. Financial institutions have paid more attention to financial risks since the financial crisis in 2008 (Silva, Kimura, \& Sobreiro, 2017). The reason is that the general financial risk leads to a decrease in the company's income, but the significant financial risks will threaten the survival of the company and resulting in significant losses even suffer bankruptcy. Therefore, financial risk control is an essential factor in company operations. Both companies have large overseas market operations. According to Pepsi's annual report, revenue in overseas markets accounted for $42 \%$ of total revenue in 2017 (Annual report, 2017). At the same time, Coca-Cola's overseas revenues account for $70 \%$ of total revenue (Annual report, 2018). According to the Bow Tie analysis (chart 1) the two companies are facing foreign exchange risks. When the appreciation or depreciation of the US dollar against other currencies will affect the company's net operating income. Two companies use hedging to avoid significant losses. Another factor that will also hurt the company's net income is the interest rate rises. Although using debt financing reduces the company's capital costs, makes companies more sensitive when facing the interest rate changes. Companies use financial derivatives such as forward contracts to circumvent interest rate risk. Credit risk is also a risk that cannot be ignored in the operation of two companies. Because the two companies have partners around the world, once the global economy deteriorates, companies will face funding problems, which may cause companies to default on payment. The default behavior of the partners will lead to problems in the company's liquidity, which will further affect the company's operations. The company uses several different financial institutions to provide commodity derivatives to minimize credit risk. 


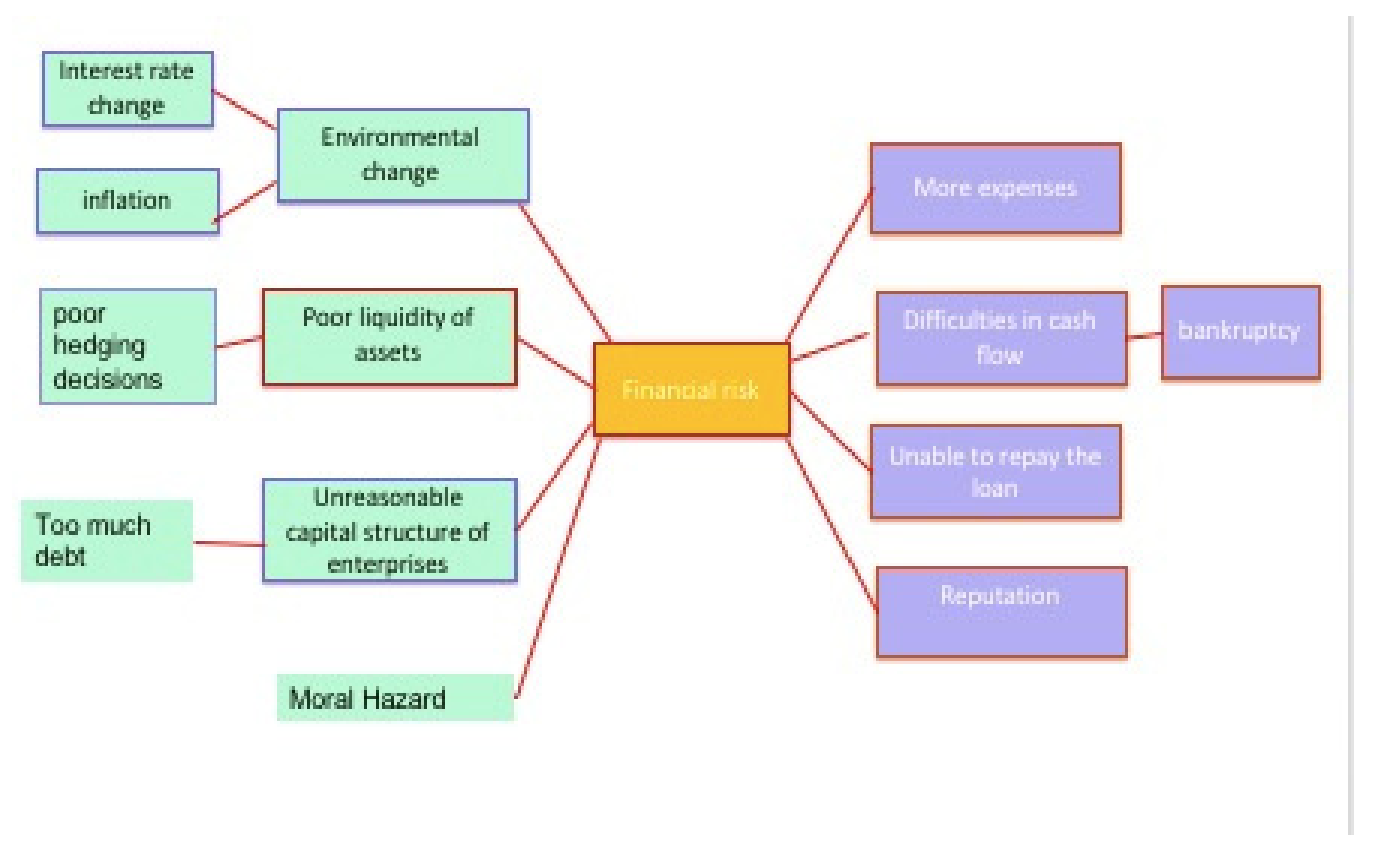

Chart 1

\subsection{Risk Analysis}

Risk management procedures are undoubtedly essential for companies to help companies identify potential risks as early as possible.

\begin{tabular}{lllll}
\hline Qualitative & Slight & Medium & Significant & Disastrous \\
& & & \\
\hline Quantify & Affect income & Affect income & Affect income & Affect \\
& $1 \%-3 \%$ & $3 \%-10 \%$ & $10 \%-20 \%$ & income \\
& & & $\begin{array}{l}\text { Higher } \\
\text { than 20\& }\end{array}$ \\
& & & &
\end{tabular}

Chart 2. Risk criteria

\begin{tabular}{lllll}
\hline Qualitative & Slight & Medium & Significant & Disastrous \\
\hline Quantify & $\begin{array}{l}\text { probability of } \\
\text { occurrence in one } \\
\text { year }\end{array}$ & $\begin{array}{l}\text { probability of } \\
\text { occurrence in one } \\
\text { year }\end{array}$ & $\begin{array}{l}\text { probability of } \\
\text { occurrence in one } \\
\text { year }\end{array}$ & $\begin{array}{l}\text { probability } \\
\text { of } \\
\text { occurrence } \\
\text { in one year }\end{array}$ \\
& $3 \%-10 \%$ & $\begin{array}{l}\text { Higher than } \\
20 \&\end{array}$ \\
\hline
\end{tabular}

Chart 3. Risk criteria

According to ISO31000, the risk management process is divided into six steps. The first step is to establish the context, which means that the organization should develop risk criteria based on its characteristics. Chart 2 is the risk standard based on the percentage of risk impact on the company's revenue. Companies can make different measures based on this standard. According to historical data, companies can also define risk criteria. For example, Figure 3 defines the risk qualitative based on the frequency of risk occurring within a year, which makes the company quantify the risk very clearly and efficiently. The second step is to identify that the company uses risk criteria to identify risks early. The analysis is the third step of the risk management process in order to 
consider the consequences of risk. The fourth step is risk evaluation which purpose is to identify the method used to reduce the impact of risk. The fifth step is risk treat. The final step is risk monitoring and reviewing for continuous monitoring of risks to provide data for the future.

\section{Conclusions}

The report focuses on risk identification and analysis of risk factors in PepsiCo and Coca-Cola. Financial risk including credit risk and interest rate risk are considerable. Then the method of risk management is given. Finally, there are three recommendations. First of all, the firms need to pay more attention to worldwide economy in case unstable economic situation results in the disadvantaged change of interest rate, which makes firms face interest rate risk. In addition, the combination of different financial institute is helpful to reduce financial risk for companies. Finally, making better products which meet consumers' need is essential to increase the performance and avoid market risk.

\section{References}

Coca-Cola Co. (2018). Coca-Cola Co, 2018 Annual Report. Retrieved from http://investor.cokeconsolidated.com/static-files/f21c57d8-31f1-4ad0-a739-5e98ee233558

Gupta, S. (2011). Mir Talks to Stan Sthanunathan, Vice President of Marketing Strategy and Insights, Coca-Cola Company. GfK-Marketing Intelligence Review, 3(1), 58-64. Retrieved from https://doi-org.ezproxy.lib.monash.edu.au/10.2478/gfkmir-2014-0056

MarketLine. (2019). PepsiCo, Inc. MarketLine Company Profile. Retrieved from https://search-ebscohost-com.ezproxy.lib.monash.edu.au/login.aspx?direct=true\&db=bth\&AN=135494173 \&site $=$ ehost-live\&scope $=$ site

McKelvey, S. M. (2006). Coca-Cola vs. PepsiCo-A" Super" Battleground for the Cola Wars?. Sport Marketing Quarterly, 15(2), 114-123. Retrieved from https://search-ebscohost-com.ezproxy.lib.monash.edu.au/login.aspx?direct=true\&db=bth\&AN=21292122\& site $=$ ehost-live \&scope $=$ site

PepsiCo, Inc. (2017). PepsiCo Inc, 2017 Annual Report. Retrieved from https://www.pepsico.com/docs/album/annual-reports/pepsico-inc-2017-annual-report.pdf

PepsiCo, Inc. (2018). PepsiCo Inc, 2018 Annual Report. Retrieved from https://www.pepsico.com/docs/album/annual-reports/pepsico-inc-2017-annual-report.pdf?sfvrsn=1f19b18d 4

Silva, K., \& Sobreiro. (2017). An analysis of the literature on systemic financial risk: A survey. Journal of Financial Stability, 28, 91-114.

Ventresca, M. J., Larsson, A., \& Kim, N. (2015). How Indra Nooyi Turned Design Thinking into Strategy: An Interview with PepsiCo's CEO: Interaction. Harvard Business Review, 93(11), 24. Retrieved from https://search-ebscohost-com.ezproxy.lib.monash.edu.au/login.aspx?direct=true\&db=bth\&AN=110486577 $\&$ site $=$ ehost-live $\&$ scope $=$ site

\section{Copyrights}

Copyright for this article is retained by the author(s), with first publication rights granted to the journal.

This is an open-access article distributed under the terms and conditions of the Creative Commons Attribution license (http://creativecommons.org/licenses/by/4.0/). 